\title{
CORRECTION TO: SYNTHESIS AND CHARACTERIZATION OF AA2024-SIO 2 NANOCOMPOSITES THROUGH THE VORTEX METHOD
}

\author{
Mehrdad Shayan (1) and Beitallah Eghbali \\ Department of Materials Science and Engineering, Sahand University of Technology, P.O. Box 51335-1996, Tabriz, Iran \\ Behzad Niroumand \\ Department of Materials Engineering, Isfahan University of Technology, 84156-83111 Isfahan, Iran
}

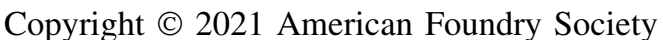

https://doi.org/10.1007/s40962-021-00582-y

\section{Correction to: \\ International Journal of Metalcasting https://doi.org/10.1007/s40962-021-00574-y}

In the original version of the online article Beitallah Eghbali's family name was misspelled. The original article has been corrected.
Publisher's Note Springer Nature remains neutral with regard to jurisdictional claims in published maps and institutional affiliations. 